\title{
Contraception and endometriosis: challenges, efficacy, and therapeutic importance
}

This article was published in the following Dove Press journal:

Open Access Journal of Contraception

27 July 2015

Number of times this article has been viewed

\author{
Edith Weisberg' \\ Ian S Fraser ${ }^{2}$ \\ 'Family Planning NSW, ${ }^{2}$ School of \\ Women's and Children's Health, \\ University of New South Wales, \\ Sydney, NSW, Australia
}

Correspondence: lan S Fraser School of Women's and Children's Health, University of New South Wales, PO Box 4044, Castlecrag, Sydney, NSW 2068, Australia

Tel +6I 408585188

Email ian.fraser@sydney.edu.au

\begin{abstract}
Endometriosis is a benign gynecological condition that is estimated to affect $10 \%$ of women in the general population and appears to be increasing in incidence. It is an estrogen-dependent inflammatory disease, and is primarily characterized by dysmenorrhea, deep dyspareunia, chronic pelvic pain, and variable effects on fertility. The symptoms may greatly affect quality of life, and symptom control may be the primary aim of initial management, while contraceptive effect is often secondary. It is estimated that $30 \%-50 \%$ of women with endometriosis have an infertility problem, so a considerable number of endometriosis sufferers will require effective, planned contraception to maximize "protection of fertility" and prevent progression of the endometriotic condition. Ideally, this contraception should also provide symptom relief and improvement of physical, mental, and social well-being. At the present time, long-term progestogens appear to be the most effective choice for meeting all of these requirements, but other options need to be considered. It is becoming increasingly recognized that hormonal contraceptive systems are necessary for prevention of disease recurrence following surgical treatment of endometriosis. The personal preferences of the woman are an integral part of the final contraceptive choice. This article discusses the advantages and disadvantages of the contraceptive options available to women with endometriosis.
\end{abstract}

Keywords: pelvic pain, disease recurrence, progestogens, delivery systems, long-acting

\section{Introduction}

Endometriosis is usually defined as a condition predominantly affecting women, where specific lesions of an inflammatory nature develop mainly in the soft tissues of the pelvis. These lesions have a histological structure with strong similarities to the glands and stroma of the endometrium, but the tissue architecture is quite different. There is great variability in the macroscopic and microscopic appearances of lesions, and in the associated clinical features and symptoms in individual women. The eutopic endometrium (in women with endometriosis) differs histologically in some features and considerably in expression of many molecular pathways from the endometrium of women without the disease. Both normal and eutopic endometrium differ from endometriotic lesions in the expression of these molecules and their pathways.

Endometriosis is a benign gynecological condition, which is estimated to affect $10 \%$ of women in the general population and appears to be increasing in incidence, explained in part by changing reproductive patterns. ${ }^{1}$ There is now a tendency for women to delay child-bearing into their thirties, thereby exposing them to an increased number of menstrual cycles and retrograde menstruation, thought to be a major factor in the development of endometriosis. It is an estrogen-dependent inflammatory 
disease, which is characterized by dysmenorrhea, deep dyspareunia, chronic pelvic pain, and variable effects on fertility. ${ }^{2}$ The etiology of endometriosis is still being elucidated, although a prevalent explanation for the presence of ectopic endometrial-like tissue within the pelvis but outside the uterus, which characterizes the disorder, is retrograde menstruation of viable endometrial fragments. Genetic predisposition appears to account for about $50 \%$ of the likelihood that a woman will develop the disease. Additionally, hormonal, environmental, and lifestyle factors also appear to be implicated, and there is a growing body of evidence that immunological factors and angiogenesis play a key role in pathogenic mechanisms. ${ }^{3}$

Endometriosis is a highly variable disease in its age of presentation, range and severity of symptomatic complaints, interference with quality of life and relationships, and extent and sites of disease. It is unpredictable in its responses to medical and surgical therapies and in rates of recurrence following treatment. This variability often means that presentation is not typical, and diagnosis may be delayed for many years from onset of symptoms. The symptoms may greatly affect quality of life, and symptom control may be the primary aim of initial management, while contraceptive effect is a secondary consideration. However, modern evidence points to significant "pregnancy failure" (miscarriage and pre-term birth) in endometriosis patients, ${ }^{4}$ necessitating careful planning, timing, and supervision of a wanted pregnancy.

Although there are a number of articles providing information on choice of a contraceptive method for women with a variety of medical conditions, endometriosis is not usually identified as requiring specific consideration.

\section{Effect on fertility}

Although endometriosis is associated with infertility, a definite cause-effect relationship and defined mechanisms have not been well established. It is estimated that 30\%-50\% of women with endometriosis have an infertility problem, ${ }^{5}$ but how much of this can be attributed directly to endometriosis is uncertain. Hence, a considerable number of endometriosis sufferers will require effective contraception that will not adversely affect or influence their endometriosis and will ideally also provide symptom relief. Many studies have attempted to identify and isolate risk factors for endometriosis. The Oxford OXGENE study found that the most common symptoms leading to a diagnosis of endometriosis were dysmenorrhea $(79 \%)$, pelvic pain $(69 \%)$, and dyspareunia $(51 \%) .{ }^{6}$ Special consideration in choice of contraceptive method needs to be given to women who exhibit these symptoms as well as adolescent young women with severe dysmenorrhea unresponsive to non-steroidal antiinflammatory agents (as potential endometriosis sufferers) and those who have previously had surgical intervention for endometriosis. There has been a very recent move to avoid undertaking laparoscopies in adolescents unless indications are overwhelming, hence in future many adolescents will be treated medically with only a clinical presumptive diagnosis of endometriosis. ${ }^{7}$

\section{Relevant aspects of pathophysiology}

The exact manner in which all the facets of the rather complex pathophysiology of endometriosis fit together remains uncertain. Much recent evidence points to the possibility that endometriosis is actually an "endometrial disease", with unique local aromatase activity (producing estrogen locally within the endometrium), ${ }^{8}$ disturbed angiogenesis, neurogenesis, cellular proliferation, apoptosis, and some progesterone resistance. All of these molecular and cellular pathways vary considerably from one patient to another. These are allied to significant retrograde menstruation and abnormal peritoneal cellular and debris surveillance and scavenging (mainly by disturbed macrophage and dendritic cell numbers and functions). This impaired surveillance appears to permit the attachment of cells and tissue fragments to the peritoneal surface, resulting in the eventual development of lesions with a significant inflammatory component. This pathophysiology is backed up by a variable genetic susceptibility, which presumably influences development of the different phenotypes of endometriosis (peritoneal, ovarian, or deep invasive lesions). The pelvic lesions of endometriosis have a different mix of molecular and cellular disturbances from the eutopic endometrium, ${ }^{9}$ but they have a clear "inflammatory" component, which presumably contributes to the chronic pelvic pain, ${ }^{10,11}$ disturbed menstrual bleeding patterns, and infertility, which are the major symptomatic hallmarks of the condition.

An improved understanding of the pathogenesis of endometriosis should allow the development of future contraceptive and therapeutic regimens that permit excellent control of symptoms and prevention of disease progression while maintaining effective contraceptive cover. Present-day hormonal contraceptive methods generally control many of these aspects of pathogenesis fairly well, but often at the cost of some side effects. Good medical management of symptoms 
often requires much "fine-tuning" of dosage and routes of delivery of different hormone combinations.

\section{Specific issues around contraceptive use in endometriosis}

For all women who wish to control their fertility and avoid an unintended pregnancy, reliable contraception is of utmost importance. Factors needing to be considered in providing good contraceptive advice for women with endometriosis are listed in Figure 1. For women with endometriosis who wish to delay pregnancy and maintain subsequent fertility, the use of a readily reversible method of contraception is an important factor. For women with symptoms suggestive of or who already have diagnosed endometriosis and wish to avoid pregnancy, an additional factor in the choice of a contraceptive method is symptom control. This is especially important in adolescents with dysmenorrhea non-responsive to non-steroidal anti-inflammatory agents, as empirical control of pain may delay the need for invasive investigations and minimize spread of the disease. ${ }^{12,13}$ The economic burden associated with endometriosis, a chronic disease, is high and similar to that of other chronic diseases (eg, Crohn's disease, rheumatoid arthritis) predominantly through the effect of endometriosis-related symptoms on productivity, impairment of quality of life, and ultimately on costs to patients and society. ${ }^{14,15}$

The quality of life in women with endometriosis is often greatly impaired, with a positive correlation between the intensity of pelvic pain and presence of anxiety symptoms, with increasing physical limitations associated with increased pain intensity. ${ }^{16}$ A systematic review has confirmed that endometriosis is associated with significant impairment in psychological and social functioning, ${ }^{17}$ and both pharmacological and surgical treatments led to improvements in patient's physical and psychological functioning, vitality, and general health. Therefore, in prescribing contraception for women with endometriosis, suspected or diagnosed, their degree of pain, emotional profile, and the effects on their quality of life should influence the choice of method.

Another goal of contraceptive choice should be directed toward prophylaxis of endometriosis progression and, following laparoscopic treatment of endometriosis, minimizing the risk of recurrence and impairment of fertility. ${ }^{18}$

Although there are many articles providing information on choice of contraceptive method for women with a variety of medical conditions, endometriosis is not usually identified as requiring specific consideration. Yet, it is clear that these women do need specific advice and counseling.

\section{Contraceptive choices}

Ideally, since endometriosis is an estrogen-dependent disease, use of progestogen-only methods of contraception is generally preferable (Table 1), especially when these methods are longacting (long-acting reversible contraception). These include oral desogestrel, more recently oral dienogest, intramuscular depot medroxyprogesterone acetate (DMPA), the subdermal etonogestrel (ENG) implant, and the levonorgestrel (LNG)releasing intrauterine system (IUS). A small proof of concept study of a progestin-releasing subdermal implant (Nestorone $^{\circledR}$ ) indicated that progestogen implants were likely to have a beneficial effect on symptoms of endometriosis. ${ }^{19}$ This is likely to apply to all LNG implants, including Jadelle ${ }^{\circledR}$ and Sinoplant ${ }^{\mathbb{B}}$. The implant and LNG IUS have the advantage of a long duration of action and the lowest pregnancy rates of all the available contraceptive methods, with a rapid return of fertility on discontinuation. All progestogen-only contraceptive methods cause variable and unpredictable changes in bleeding patterns, and as they do not suppress ovulation,

- Effective contraception

- Endometriosis symptom control

- Desire for future pregnancy (women wanting children should be encouraged to attempt pregnancy as soon as possible)

- Prevention of progression of endometriosis

- Fertility control plus post-surgical prevention of recurrence

- Effect on physical, mental, and social well-being

- Personal preferences

Figure I Factors that need to be considered in contraceptive choices for women with endometriosis. 
Table I Advantages and disadvantages of different contraceptive options in women with suspected or diagnosed endometriosis in order of preference

\begin{tabular}{|c|c|c|c|c|c|c|c|c|}
\hline Method & $\begin{array}{l}\text { Estrogen } \\
\text { containing }\end{array}$ & $\begin{array}{l}\text { Pain } \\
\text { relief }\end{array}$ & $\begin{array}{l}\text { Highly effective } \\
\text { contraception }\end{array}$ & $\begin{array}{l}\text { Long- } \\
\text { acting }\end{array}$ & $\begin{array}{l}\text { Cycle } \\
\text { control }\end{array}$ & $\begin{array}{l}\text { Blood } \\
\text { loss }\end{array}$ & $\begin{array}{l}\text { Effect } \\
\text { on BMD }\end{array}$ & $\begin{array}{l}\text { Possible functional } \\
\text { ovarian cysts }\end{array}$ \\
\hline $\begin{array}{l}\text { Progestogen } \\
\text { only pill }\end{array}$ & No & Yes & $\begin{array}{l}\text { Yes, but compliance } \\
\text { problematic }\end{array}$ & No & Variable & Variable & No & Yes \\
\hline $\begin{array}{l}\text { Subdermal } \\
\text { implant }\end{array}$ & No & Yes & Yes & $\begin{array}{l}\text { Yes } \\
3 \text { years }\end{array}$ & Variable & Variable & No & Yes \\
\hline LNG IUS & No & Yes & Yes & $\begin{array}{l}\text { Yes } \\
5 \text { years }\end{array}$ & Variable & Reduced & No & Yes \\
\hline DMPA & No & Yes & Yes & 3 monthly & $\begin{array}{l}\text { Amenorrhea } \\
\text { common }\end{array}$ & Reduced & $\begin{array}{l}\text { Yes but } \\
\text { reversible }\end{array}$ & Rare \\
\hline $\begin{array}{l}\text { COC* } \\
\text { continuous }\end{array}$ & Yes & Yes & $\begin{array}{l}\text { Yes, but compliance } \\
\text { problematic }\end{array}$ & $\begin{array}{l}\text { No } \\
\text { daily use }\end{array}$ & Variable & Reduced & No & No \\
\hline $\begin{array}{l}\text { COC* } \\
\text { cyclic }\end{array}$ & Yes & Variable & $\begin{array}{l}\text { Compliance problematic } \\
\text { in adolescents }\end{array}$ & $\begin{array}{l}\text { No } \\
\text { daily use }\end{array}$ & Good & Reduced & No & No \\
\hline CVR & Yes & Probable & Yes & $\begin{array}{l}\text { No } \\
\text { monthly }\end{array}$ & Good & Reduced & No & No \\
\hline $\begin{array}{l}\text { Transdermal } \\
\text { patch }\end{array}$ & Yes & Probable & Yes & $\begin{array}{l}\text { No } \\
\text { weekly }\end{array}$ & Good & Reduced & No & No \\
\hline
\end{tabular}

Note: *Preferably an estradiol-containing COC.

Abbreviations: BMD, bone mineral density; COC, combined oral contraceptive; CVR, contraceptive vaginal ring; DMPA, depot medroxyprogesterone acetate; LNG, levonorgestrel; IUS, intrauterine system.

are associated with a small increase in functional follicular cysts. These may transiently affect pain and bleeding. Women considering these methods require careful counseling in order to make an informed choice.

\section{Progestogen-releasing IUS}

The LNG IUS has an efficacy comparable with that of sterilization, with a pregnancy rate of $0.2 \%$ in the first 12 months of use and $0.5 \%-1.1 \%$ over 5 years of use. ${ }^{20}$ The LNG IUS is suitable for use by nulliparous women, but they have a 1.6-fold increased risk of a difficult insertion. ${ }^{21}$ Uterine perforation is rare $(0.53 / 1,000$ insertions), but is higher in post-partum and in lactating women. ${ }^{22}$ Spontaneous expulsion of the device can occasionally occur, usually in the first 3 months of use, at a rate of about $0.8 \%$, and is no different in nulliparous or parous women. The ectopic pregnancy rate is extremely low at 0.02 per 100 woman-years compared with $0.3-0.5$ per 100 woman-years for those not using any contraception. ${ }^{20}$ However, there are no specific data to indicate whether these numbers are different in women with endometriosis. Anecdotal comment suggests that insertion may be more difficult in the endometriosis patient with a tender uterus, and perhaps spontaneous expulsion may be higher. The very recent marketing of a slimmer, lower dose LNG IUS (releasing $12 \mu$ g of LNG daily; Jaydess ${ }^{\circledR}$, Skyla $^{\circledR}$ ), may allow easier insertion in some nulliparous women.

The LNG IUS, as well as being a highly effective contraceptive, has been shown to decrease the severity of dysmenorrhea, pelvic pain, and deep dyspareunia, ${ }^{23}$ as well as decrease the size of ovarian endometriotic lesions..$^{24,25}$

The main mode of action of the LNG IUS is at a uterine level, with endometrial atrophy and an inflammatory response maximal at 3 months and maintained for the life of the device. ${ }^{26,27}$ It also increases cervical mucus viscosity, impeding sperm penetration, and releases glycodelin A within the uterine glands, inhibiting fertilization and implantation. There is some inhibition of ovulation in the first 12 months, but most cycles are ovulatory. Since serum estradiol levels are generally within the normal range, it is not entirely clear why the LNG IUS should offer a symptomatic advantage for women with endometriosis. It has been postulated that the atrophic changes induced in the endometrium may similarly occur in the ectopic endometriotic lesions. ${ }^{28}$ A number of other mechanisms for the effectiveness of the LNG IUS in controlling pain have been postulated, including a reduction in local angiogenesis, reduction in uterine innervation, reduction in pelvic vascular "congestion", and an increase in apoptosis in lesions. ${ }^{29}$ Undoubtedly, the very thin endometrium and minimal bleeding in established LNG IUS users will minimize any ongoing retrograde menstruation.

Most women using the LNG IUS experience irregular bleeding. Spotting and frequent or prolonged bleeding may initially be experienced by up to $35 \%$ of contraceptive LNG IUS users in the first 3-5 months of use. By 9 months, 50\% experience infrequent, light bleeding, and amenorrhea occurs in a further $15 \%$. At 5 years, $23 \%$ of women are amenorrheic 
and $77 \%$ experience infrequent bleeding, a useful effect for women with the heavy menstrual bleeding sometimes associated with endometriosis. There are no trials to show that endometriosis subjects have similar experience. Counseling women about these bleeding disturbances prior to IUS use is important.

Hormonal side effects such as mood changes, acne, breast tenderness, and headaches may occur in about 3\%-5\% of users initially but diminish over time. ${ }^{30}$ Since many women with endometriosis may wish to delay pregnancy or have completed their families, the LNG IUS, with a lifespan up to 5 years, which can also alleviate pelvic pain and heavy bleeding, is an ideal method with rapid return of fertility on removal if required. ${ }^{31}$

\section{Subdermal progestogen implants}

Two subdermal implants, a single ENG rod, with a 3-year lifespan, and an LNG two-rod system with a 5-year lifespan, are currently in use. The LNG implant has not been marketed as widely as the ENG rod in developed countries but is used widely in under-resourced countries because it is equally as effective but cheaper.

The ENG implant prevents the luteinizing hormone surge so that ovarian follicular development usually occurs without ovulation. The LNG implant disrupts follicular growth and the ovulatory process, causing a variety of changes that range from anovulation to insufficient luteal function. ${ }^{32}$ Both implants increase the viscosity of cervical mucus and produce an endometrium that is thin but not atrophic. Both are highly effective methods, with a pregnancy rate of $0.01 \%-0.1 \%$ per year in typical use. ${ }^{33}$ The woman rapidly returns to her normal fertility when the implants are removed. Because the implants contain no estrogen, the most common side effects are changes in menstrual bleeding patterns, ${ }^{34}$ which sometimes lead to requests for removal. ${ }^{35}$ Most other common side effects are similar to those experienced by women who use other hormonal contraceptives. The finding of ovarian cysts or enlarged ovarian follicles during the 1st year of use of ENG and LNG implants is common and transient, and should not be interpreted as pathological, ${ }^{36}$ but in women with endometriosis it may be difficult to distinguish between functional and endometriotic cysts unless a good quality transvaginal ultrasound examination is performed.

Although there are only limited data, implants appear to be effective in decreasing the pain associated with endometriosis. Walch et $\mathrm{al}^{37}$ found that by 6 months of use of the ENG implant the average decrease in pain was $68 \%$. A Thai study of the ENG implant in 50 women with endometriosis found that the visual analog scale score for pain reduced from 7.08 \pm 2.09 to $0.84 \pm 1.67$ at the 12 th week of treatment. Regular menstruation, amenorrhea, spotting, and breakthrough bleeding were reported by $42 \%, 28 \%, 26 \%$, and $4 \%$ of women, respectively. Eighty percent of women were satisfied or very satisfied with the implant while $10 \%$ were uncertain. All continued implant use at the end of the study. ${ }^{38}$

\section{Depot medroxyprogesterone acetate}

DMPA is available either as an intramuscular injection (150 mg once every 3 months) or a subcutaneous injection (106 mg) which can be self-administered. With a failure rate of $0.5 \%$ and a mode of action primarily by suppression of ovulation with ancillary effects on the endometrium and cervical mucus, it is an effective contraceptive for women with endometriosis. It also appears to have an effect on pain scores, with an estimated 53\%-90\% decrease in pain ${ }^{37,39}$ and an $80 \%$ improvement in dyspareunia during treatment. The subcutaneous injection appears to be equally as effective as the intramuscular injection, both as a contraceptive and in pain relief. ${ }^{40,41}$ However, a Cochrane review of 13 studies concluded that there was only limited evidence to support the use of progestogens, including DMPA, for the relief of endometriosis-related pain. ${ }^{42}$

A concern about DMPA is its effect on bone density, which decreases in the first 1-2 years of use and then stabilizes, which is similar irrespective of injection route. ${ }^{43}$ However, a number of studies both in young and older women has shown that bone mineral density is substantially or fully reversible on cessation of DMPA. ${ }^{44,45}$ DMPA should not be recommended for women who plan to attempt pregnancy within the next 2 years as DMPA can result in a delay in the return of fertility for up to 18 months. As with all progestogen-only contraception methods, DMPA causes menstrual irregularities, with $50 \%$ of women exhibiting amenorrhea by 12 months of use. Although weight gain up to $2 \mathrm{~kg}$ per year has been reported, a Cochrane review found limited evidence of weight gain associated with the use of all progestogen-only contraceptives and recommended counseling about typical weight gain to help reduce discontinuation rates due to perception of weight gain. ${ }^{46}$

\section{Oral progestogen-only methods}

Of the four main oral progestogen-only methods, ie, LNG $30 \mu \mathrm{g}$, norethisterone $350 \mu \mathrm{g}$, desogestrel $75 \mu \mathrm{g}$, and dienogest $2 \mathrm{mg}$, the latter two are preferable since they inhibit ovulation in $97 \%$ of cycles and produce significantly lower 
estradiol levels. ${ }^{47}$ They are effective methods of contraception when taken continuously, with a Pearl Index of 0.41 per 100 woman-years. It has the additional benefit of a 12-hour window following a missed pill, which may facilitate timely pill taking and improve efficacy. Return of fertility on cessation is rapid, with an average of 17.2 days from last tablet intake to ovulation. ${ }^{48}$ Bleeding patterns are variable, with almost $50 \%$ of users reporting infrequent bleeding or amenorrhea by 11-13 months of use. There are no data specific to pain associated with endometriosis in women without prior surgical intervention; however, by 3-4 months of starting the desogestrel progestogen-only pill, dysmenorrhea in $93 \%$ of 406 women resolved or considerably improved and analgesic use dropped from $70 \%$ at baseline to $8 \% .{ }^{49}$

\section{Combined estrogen/progestogen contraceptives}

Combinations of estrogens and progestogens for contraception can be delivered orally, transdermally as a skin patch, or intravaginally as a ring. All are equally efficacious as contraceptives, and the route of administration depends on the personal preference of the individual woman. All combined hormonal contraceptives carry a small increased risk of venous thromboembolism associated with the estrogen component. Best evidence indicates that venous thromboembolism rates in non-users of reproductive age approximate 4-5/10,000 women per year, while rates in oral contraceptive users are in the range of 9-10/10,000 women per year. This risk is increased in women with genetic thrombophilias such as Factor V Leiden mutations, raised body mass index, sedentary lifestyle, and cigarette smoking. There is no evidence that side effects due to combined oral contraceptives (COCs) differ in women with and without endometriosis.

In recent years, the choice of oral estrogen/progestogen combinations has increased with the advent of several new progestogens, including dienogest, drospirenone, and nomegestrol acetate, and recently the use of estradiol-17 $\beta$ instead of ethinyl estradiol. Oral preparations of ethinyl estradiol in combination with different progestogens have been used extensively for many years for the management of dysmenorrhea associated with endometriosis. A number of studies using COCs with different progestogens, eg, desogestrel, ${ }^{50}$ gestodene,${ }^{51}$ norethisterone, ${ }^{52}$ drospirenone,${ }^{53}$ LNG suggest that all COCs are effective in ameliorating dysmenorrhea in the majority of women with endometriosis. As there are no comparative studies to suggest that one COC may be more effective than others, the initial use of any lowdose monophasic COC is appropriate.
COCs provide effective contraception, and some studies have shown that they can reduce the size of endometriomas. ${ }^{52,53}$ This positive effect appears to be due to the downregulation of cell proliferation and an increase in the rate of apoptosis in eutopic endometrium and cyst lining. ${ }^{54}$ However, a Cochrane review found that comparative studies between COCs and other treatments for pelvic pain were inadequate to fully evaluate the role of COCs. ${ }^{55}$ Nevertheless, COCs provide a low-cost, effective, and acceptable method of contraception that can ameliorate dysmenorrhea, and are of benefit to many women. Continuous rather than cyclical administration of a COC may be more efficacious for control of dysmenorrhea because it is associated with less frequent menstrual bleeding. ${ }^{50,56}$ However, careful counseling is required to ensure unpredictable bleeding is acceptable.

There has been debate in the literature regarding the role that COCs may play in the development of endometriosis. ${ }^{57}$ A meta-analysis of 18 studies found the relative risk of development of endometriosis was 1.19 in ever users of COCs, 0.63 in current users, and 1.21 in past users. ${ }^{18}$ To clarify this, Chapron et $\mathrm{al}^{57}$ carried out a cross-sectional study of women without visible endometriosis at surgery compared with women with surgically diagnosed endometriosis, and found that women who had previously used COCs for the management of severe dysmenorrhea were more likely to be diagnosed with endometriosis at a later date, a finding confirmed by Vercellini et al. ${ }^{58}$ Although there is no clear scientific proof, it suggests that there is a protective effect against progression of endometriosis by COCs, and past use of COCs for severe dysmenorrhea may act as a marker for endometriosis and contributing to a delay in recognition of the disease, for up to 7 years after onset of symptoms (Figure 2).

There has been only one report of the comparative use of the contraceptive vaginal ring and transdermal patch in women with endometriosis. The women started on continuous treatment with both methods, but almost $50 \%$ in each group reverted to cyclic use because of irregular bleeding. Pain symptoms were reduced with both methods, but the ring was more effective in controlling symptoms in women with deep rectovaginal lesions. The women using the contraceptive vaginal ring method were more satisfied with the treatment than women using the patch. ${ }^{18}$

\section{Contraception after surgical treatment for endometriosis}

Following surgical management of endometriosis, effective contraception is important for those women who have 

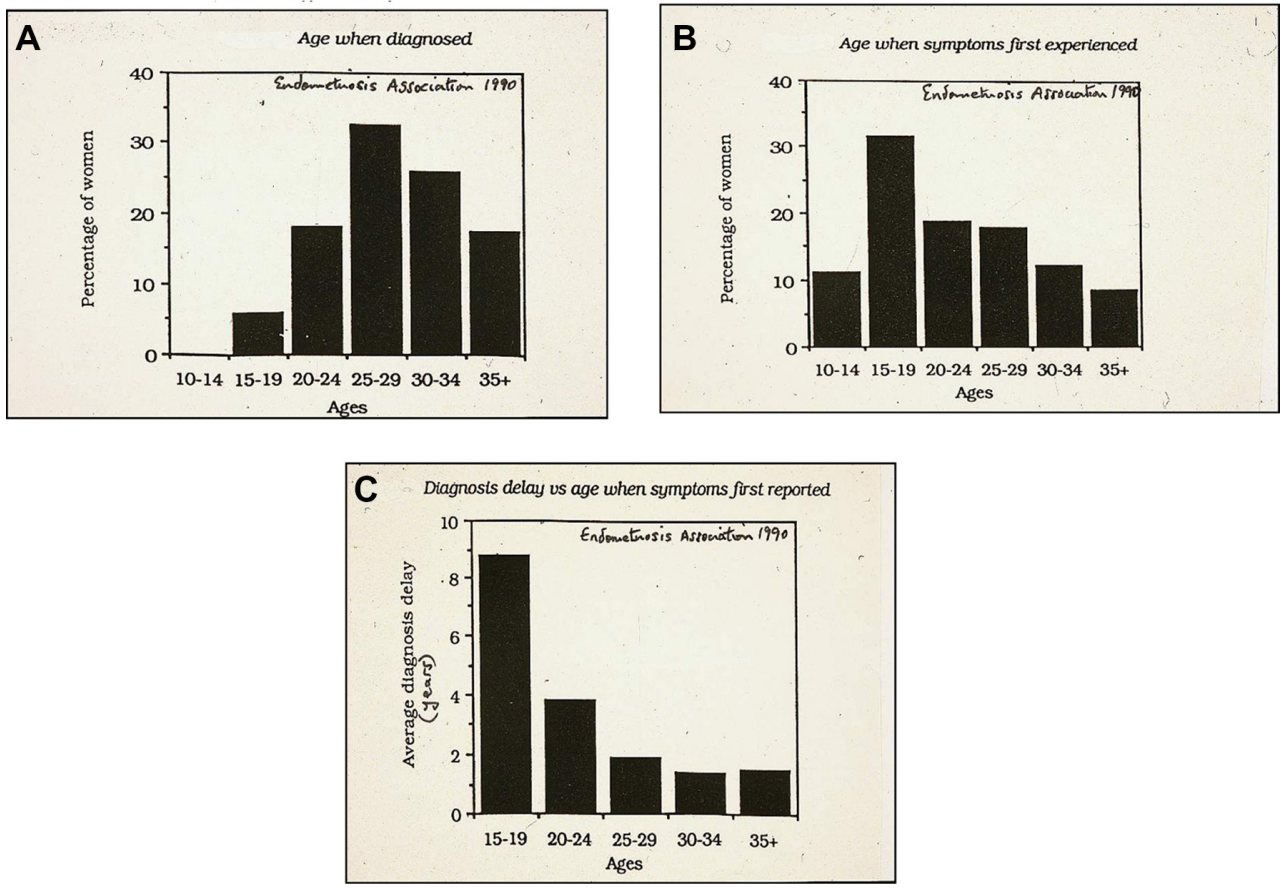

Figure 2 Relationship between onset of symptoms and age at diagnosis of endometriosis.

Notes: (A) Age at diagnosis; (B) Age at first symptoms; (C) Diagnostic delay. Figure courtesy of the Victorian Endometriosis Association (Australia) 1990.

completed their families or desire to postpone pregnancy. The contraceptive method chosen should also carry the benefit of preventing recurrence of pelvic pain, endometriomas, or other endometriosis lesions. In this context, continuous use of COCs appears to be associated with reduced recurrence rates of dysmenorrhea, pelvic pain, and endometrioma compared with cyclic use. ${ }^{59,60}$ However, this therapy needs to be used long-term or until pregnancy is desired. Vercellini et $\mathrm{al}^{61}$ found that 3 years of cyclic COC post-surgery prevented recurrence of endometrioma in $50 \%$ of women. A further review by Vercellini et al ${ }^{62}$ suggests that suppression of ovulation is important for prevention of recurrence of endometrioma.

Use of the LNG IUS following conservative surgery for endometriosis provides highly effective contraception plus pain control for most women with moderate or severe pain. Tanmahasamut et $\mathrm{al}^{63}$ found that such use of the LNG IUS was acceptable for long-term therapy and improved both the physical and mental health of women. A small, randomized comparative study of an estradiol valerate/dienogest pill against the LNG IUS found that both were equally effective for pain control and for reducing recurrence rates. However, the IUS resulted in significantly greater patient satisfaction. A Cochrane review concluded that there was limited but consistent evidence that postoperative use of the $\mathrm{LNG}$ IUS reduced the recurrence of dysmenorrhea in women with endometriosis. ${ }^{64}$ DMPA also appears to have a beneficial effect on control of pain following conservative surgery for endometriosis. It provides low-cost, effective contraception but has the disadvantage of an unpredictable delay of some months in the return of fertility after cessation for those women who still desire a pregnancy. ${ }^{65}$

\section{Contraception for adolescents with suspected or diagnosed endometriosis}

Endometriosis has been shown to occur in adolescents as young as 10 years, and can be a major cause of chronic pelvic pain and dysmenorrhea, which are greatly disruptive to lifestyle. ${ }^{66}$ In fact, symptoms of endometriosis often begin in adolescence for many women later diagnosed with the disease. Adolescents have been shown to frequently have a 10-year delay from the onset of symptoms to the diagnosis being made (Figure 2). Hence, there is a real need for physicians to have a high degree of suspicion of underlying endometriosis in adolescents with moderate to severe dysmenorrhea or other chronic pelvic pain, especially if a family history is present. The aim of using hormonal methods of contraception in young women with endometriosis should be to provide effective fertility control and at the same time alleviate associated pain and progression of the disease. 
Continuous administration of COCs is usually the method recommended for adolescents with dysmenorrhea likely due to endometriosis. However, adolescents may have problems adhering to daily oral medication and may find any associated irregular bleeding difficult to manage. Long-acting and reversible progestogen contraceptives are appropriate and highly effective methods of contraception, which require no action on the part of the user after insertion, and have been demonstrated to provide substantial alleviation of pain. Since endometriosis is an estrogen-dependent disease, long-acting reversible contraceptives are preferable to COCs for longterm management in adolescents. The American College of Obstetricians and Gynecologists Committee on Adolescent Health Care, Long-Acting Reversible Contraception Working Group, in their latest opinion, have stated that long-acting reversible contraceptives should be considered as first-line contraceptives for adolescents. ${ }^{67}$

DMPA has been widely used by adolescents and shown to be highly effective for both contraception and pain control. However, concerns have been raised about the long-term effects of bone loss on peak bone mass associated with use of DMPA in young adolescents. A study of long-term DMPA in young women aged 12-18 years found that although bone mineral density (BMD) declined during use, long-term loss did not continue, and most bone was fairly rapidly replaced following discontinuation. Harel et $\mathrm{al}^{44}$ found that bone mineral density returned to baseline levels within 60 weeks of discontinuation of DMPA.

DMPA has been associated with weight gain, which is of particular concern to many young women. Young DMPA users have been shown to gain more weight than COC users, especially if they are overweight at the start of treatment. ${ }^{68,69}$ In the USA, adolescents have shown an interest in using the subcutaneous form of DMPA, and at least a third were found to be capable of self-administration after brief education and minimal assistance. ${ }^{70}$ There are no specific data on the long-term effects of DMPA use in young women with endometriosis.

The LNG IUS is an excellent option for young women, both as a contraceptive and for alleviation of endometriosisassociated symptoms. However, there is still some reluctance on the part of clinicians to use the LNG IUS in nulliparous adolescents. Insertion in nulliparae is usually without difficulty in more than $80 \%$ of cases. ${ }^{71}$ Rates of expulsion, bleeding, and amenorrhea in adolescent users appear to be similar to those reported by older women. ${ }^{72}$ In a randomized trial, young women aged 18-25 years using the LNG IUS had more significant alleviation of dysmenorrhea, although not specifically related to endometriosis, compared with COCs. ${ }^{73}$ The LNG IUS has been successfully used in adolescents with surgically diagnosed endometriosis for pain control. The authors have strongly recommended insertion at the end of the diagnostic procedure. ${ }^{74}$

Although there are no data on the use of the ENG implant alone in young women with endometriosis, it is a useful method of contraception, and offers the additional benefit of a reduction in pelvic pain. There is one case report of simultaneous and highly successful use of the ENG implant in conjunction with the LNG IUS in a 15-year-old with severe symptoms unresponsive to other therapies. ${ }^{75}$ Continuation rates in young women aged 12-18 years are better for the ENG subdermal implant than for the COC or DMPA. ${ }^{76,77}$ All adolescents using hormonal methods should generally be advised to use condoms as well for prevention of sexually transmitted infections.

\section{Conclusion}

The contraceptive choice in women with endometriosis must fulfill two main objectives, ie, offer highly effective fertility control and provide reliable pain relief for prolonged periods, with fairly rapid reversal if a pregnancy is desired. Ideally, the method should also prevent progression of the disease or recurrence after surgical management. In choice of a method, many additional factors may need to be taken into account, including the side effect profile, the ongoing cost, and the preference of the woman, who should always be made aware of the benefits and risks to enable her to make an informed decision.

\section{Disclosure}

ISF has given lectures, has participated on advisory boards, and received expenses and honoraria from Bayer Healthcare, Merck/MSD, Daiichi Sankyo, and Vifor Pharma. He has received occasional grants from these companies to undertake ethically approved clinical research, the results of which have been published in international journals. EW has given lectures, participated on advisory boards, and received expenses and honoraria from Bayer Healthcare and Merck/MSD. She has undertaken ethically approved clinical research and received grants from these companies.

\section{References}

1. Viganò P1, Parazzini F, Somigliana E, Vercellini P. Endometriosis: epidemiology and aetiological factors. Best Pract Res Clin Obstet Gynaecol. 2004;18:177-200.

2. Streuli I, de Ziegler D, Santulli P, et al. An update on the pharmacological management of endometriosis. Expert Opin Pharmacother. 2013;14: 291-305. 
3. Larosa M, Facchini F, Pozzoli G, Leone M, Grande M, Monica B. Endometriosis: aetiopathogenetic basis. Urologia. 2010;77 Suppl 17: $1-11$.

4. Falconer H. Pregnancy outcomes in women with endometriosis. Semin Reprod Med. 2013;31:178-182.

5. Macer ML, Taylor HS. Endometriosis and infertility: a review of the pathogenesis and treatment of endometriosis-associated infertility. Obstet Gynecol Clin North Am. 2012;39:535-549.

6. Sinaii N, Plumb K, Cotton L, et al. Differences in characteristics among 1,000 women with endometriosis based on extent of disease. Fertil Steril. 2008;89:538-545.

7. European Society of Human Reproduction and Embryology. Endometriosis Guideline Development Group. Management of women with endometriosis: Guideline of the European Society of Human Reproduction and Embryology. Available from: http://endometriosis.eshre.eu/docs/ESHREguidelineonendometriosis2013_3.pdf. Accessed July 16, 2014.

8. Noble LS, Simpson ER, Johns A, Bulun SE. Aromatase expression in endometriosis. J Clin Endocrinol Metab. 1996;81(1):174-179.

9. Al-Jefout M, Tokushige N, Hey-Cunningham AJ, Manconi F, Ng C, Schulke L, et al. Microanatomy and function of the eutopic endometrium in women with endometriosis. Expert Rev Obstet Gynecol. 2009;4(1):61-79.

10. Fraser IS, Tokushige N, Hey-Cunningham, Berbic M, Ng CHM. Pelvic mechanisms involved in the pathophysiology of pain in endometriosis. In: Giudice L, Evers JLH, Healy DL, editors. Endometriosis: Science and Practice. Blackwell Publishing: London, UK; 2012; Chap 21: 212-229.

11. Berbic M, Hey-Cunningham AJ, $\mathrm{Ng} \mathrm{C}$, et al. The role of the immune response in endometriosis. In: Mitchell LA, editor. Endometriosis. symptoms, diagnosis and treatments. Nova Science Publishers Inc. Chap 2, 2009:1-32.

12. Harel Z. Dysmenorrhea in adolescents and young adults: etiology and management. J Pediatr Adolesc Gynecol. 2006;19:363-371.

13. Harada T. Dysmenorrhea and endometriosis in young women. Yonago Acta Med. 2013;56:81-84.

14. Klein S, D'Hooghe T, Meuleman C, Dirksen C, Dunselman G, Simoens $\mathrm{S}$. What is the societal burden of endometriosis-associated symptoms? A prospective Belgian study. Reprod BioMed Online. 2014;28:116-124.

15. Simoens S, Dunselman G, Dirksen C, et al. The burden of endometriosis: costs and quality of life of women with endometriosis and treated in referral centres. Hum Reprod. 2012;27:1292-1299.

16. Sepulcria RP, Amaral VF. Depressive symptoms, anxiety, and quality of life in women with pelvic endometriosis. Eur J Obstet Gynecol Reprod Biol. 2009; 142:53-56.

17. Gao X, Yeh YC, Outley J, Simon J, Botteman M, Spalding J. Healthrelated quality of life burden of women with endometriosis: a literature review. Curr Med Res Opin. 2006;22:1787-1797.

18. Vercellini P, Barbara G, Somigliana E, Bianchi S, Abbiati A, Fedele L. Comparison of contraceptive ring and patch for the treatment of symptomatic endometriosis. Fertil Steril. 2010;93:2150-2161.

19. Ylanen K, Laatikainen T, Lähteenmäki P, Moo-Young AJ. Subdermal progestin implant (Nesterone) in the treatment of endometriosis: clinical response to various doses. Acta Obstet Gynecol Scand. 2003;82: $167-172$.

20. Mansour D. The benefits and risks of using a levonorgestrel-releasing intrauterine system for contraception. Contraception. 2012;85: 224-234.

21. Weisberg E. Developments in contraception. Expert Opin Pharmacother. 2014;15:203-210.

22. Kaislasuo J, Suhonen S, Gissler M, Lähteenmäki P, Heikinheimo O. Intrauterine contraception: incidence and factors associated with uterine perforation - a population-based study. Hum Reprod. 2012;27: 2658-2663.

23. Vercellini P, Aimi G, Panazza S, De Giorgi O, Pesole A, Crosignani PG. A levonorgestrel-releasing intrauterine system for the treatment of dysmenorrhea associated with endometriosis: a pilot study. Fertil Steril. 1999;72:505-508.
24. Lockhat FB, Emembolu JO, Konje JC. The evaluation of the effectiveness of an intrauterine-administered progestogen (levonorgestrel) in the symptomatic treatment of endometriosis and in the staging of the disease. Hum Reprod. 2004;19:179-184.

25. Lockhat FB, Emembolu JO, Konje JC. The efficacy, side-effects and continuation rates in women with symptomatic endometriosis undergoing treatment with an intra-uterine administered progestogen (levonorgestrel): a 3 year follow-up. Hum Reprod. 2005;20: 789-793.

26. Ortiz ME, Croxatto HB. Copper-T intrauterine device and levonorgestrel intrauterine system: biological bases of their mechanism of action. Contraception. 2007;75:S16-S30.

27. Lähteenmäki P, Bardin CW, Eloma K, et al. Selection and performance of the levonorgestrel-releasing intrauterine system. Acta Obstet Gynecol Scand. 1997;164:69-74.

28. Hidalgo M1, Bahamondes L, Perrotti M, Diaz J, Dantas-Monteiro C, Petta C. Bleeding patterns and clinical performance of the levonorgestrel-releasing intrauterine system (Mirena) up to two years. Contraception. 2002;65:129-132.

29. Maruo T, Laoag-Fernandez JB, Pakarinen P, Murakoshi H, Spitz IM, Johansson E. Effects of the levonorgestrel-releasing intrauterine system on proliferation and apoptosis in the endometrium. Hum Reprod. 2001;16:2103-2108.

30. Luukkainen T, Pakarinen P, Toivonen J. Progestin-releasing intrauterine systems. Semin Reprod Med. 2001;19:355-363.

31. Bahamondes L, Petta CA, Fernandes A, Monteiro I. Use of the levonorgestrel-releasing intrauterine system in women with endometriosis, chronic pelvic pain and dysmenorrhea. Contraception. 2007;75 Suppl 6:S134-S139.

32. Croxatto HB, Mäkäräinen L. The pharmacodynamics and efficacy of Implanon. An overview of the data. Contraception. 1998;58: 91S-97S.

33. Meirik O, Fraser IS, d'Arcangues C; WHO Consultation on Implantable Contraceptives for Women. Implantable contraceptives for women. Hum Reprod Update. 2003;9:49-59.

34. Mansour D, Korver T, Marintcheva-Petrova M, Fraser IS. The effects of Implanon on menstrual bleeding patterns. Eur J Contracept Reprod Health Care. 2008;13 Suppl 1:13-28.

35. Weisberg E, Fraser I. Australian women's experience with Implanon. Aust Fam Physician. 2005;34:694-696.

36. Hidalgo MM, Lisondo C, Juliato CT, Espejo-Arce X, Monteiro I, Bahamondes L. Ovarian cysts in users of Implanon ${ }^{\circledR}$ and Jadelle ${ }^{\circledR}$ subdermal contraceptive implants. Contraception. 2006;73:532-536.

37. Walch K, Unfrieda G, Hubera J, et al. Implanon ${ }^{\circledR}$ versus medroxyprogesterone acetate: effects on pain scores in patients with symptomatic endometriosis - a pilot study. Contraception. 2009;79:29-34.

38. Ponpuckdee J, Taneepanichskul S. The effects of Implanon in the symptomatic treatment of endometriosis. J Med Assoc Thai. 2005;88 Suppl 2:S7-S10.

39. Crosignani PG, Luciano A, Ray A, Bergqvist A. Subcutaneous depot medroxyprogesterone acetate versus leuprolide acetate in the treatment of endometriosis-associated pain. Hum Reprod. 2006;21: 248-256.

40. Simon MA, Shulman LP. Subcutaneous versus intramuscular depot methoxyprogesterone acetate: a comparative review. Womens Health (Lond Engl). 2006;2:191-197.

41. Schlaff WD, Carson SA, Luciano A, Ross D, Bergqvist A. Subcutaneous injection of depot medroxyprogesterone acetate compared with leuprolide acetate in the treatment of endometriosis-associated pain. Fertil Steril. 2006;85:314-325.

42. Brown J, Kives S, Akhtar M. Progestagens and anti-progestagens for pain associated with endometriosis. Cochrane Database Syst Rev. 2012;3:CD002122.

43. Kaunitz AM, Darney PD, Ross D, Wolter KD, Speroff L. Subcutaneous DMPA vs. intramuscular DMPA: a 2-year randomized study of contraceptive efficacy and bone mineral density. Contraception. 2009;80: $7-17$. 
44. Harel Z, Johnson CC, Gold MA, et al. Recovery of bone mineral density in adolescents following the use of depot medroxyprogesterone acetate contraceptive injections. Contraception. 2010;81:281-291.

45. Renner RM, Adelman AB, Kaunitz AM. Depot medroxyprogesterone acetate contraceptive injections and skeletal health. Womens Health (Lond Engl). 2010;6:339-342.

46. Lopez LM, Edelman A, Chen M, Otterness C, Trussell J, Helmerhorst FM. Progestin-only contraceptives: effects on weight. Cochrane Database Syst Rev. 2013;7:CD008815.

47. Rice CF, Killick SR, Dieben T, Coelingh Bennink H. A comparison of the inhibition of ovulation achieved by desogestrel $75 \mu \mathrm{g}$ and levonorgestrel 30 g daily. Hum Reprod. 1999;14:982-995.

48. Korver T, Klipping C, Heger-Mahn D, Duijkers I, van Osta G, Dieben T. Maintenance of ovulation inhibition with the $75-\mu \mathrm{g}$ desogestrel-only contraceptive pill $\left(\right.$ Cerazette $^{\sqrt{\mathbb{R}}}$ ) after scheduled 12-h delays in tablet intake. Contraception. 2005;71:8-13.

49. Ahrendt HJ, Karckt U, Pichl T, Mueller T, Ernst U. The effects of an oestrogen-free, desogestrel-containing oral contraceptive in women with cyclical symptoms: results from two studies on oestrogen-related symptoms and dysmenorrhoea. Eur J Contracept Reprod Health Care. 2007; 12:354-361

50. Vercellini P, Frontino G, De Giorgi O, Pietropaolo G, Pasin R, Crosignani PG. Continuous use of an oral contraceptive for endometriosisassociated recurrent dysmenorrhea that does not respond to a cyclic pill regimen. Fertil Steril. 2003;80:560-563.

51. Ferrari S, Persico P, Di Puppo F, et al. Continuous low-dose oral contraceptive in the treatment of colorectal endometriosis evaluated by rectal endoscopic ultrasonography. Acta Obstet Gynecol Scand. 2012;91:699-703.

52. Harada T, Momoeda M, Taketani Y, Hoshiai H, Terakawa N. Low-dose oral contraceptive pill for dysmenorrhea associated with endometriosis: a placebo-controlled, double-blind, randomized trial. Fertil Steril. 2008;90:1583-1588.

53. Mabrouk M, Solfrini S, Frascà C, et al. A new oral contraceptive regimen for endometriosis management: preliminary experience with 24/4day drospirenone/ethinylestradiol $3 \mathrm{mg} / 20 \mathrm{mcg}$. Gynecol Endocrinol. 2012;28:451-454

54. Meresman GF, Augé L, Barañao RI, Lombardi E, Tesone M, Sueldo C. Oral contraceptives suppress cell proliferation and enhance apoptosis of eutopic endometrial tissue from patients with endometriosis. Fertil Steril. 2002;77:1141-1147.

55. Davis L, Kennedy SS, Moore J, Prentice A. Modern combined oral contraceptives for pain associated with endometriosis. Cochrane Database Syst Rev. 2007;3:CD001019.

56. Guzick DS, Huang LS, Broadman BA, Nealon M, Hornstein MD. Randomized trial of leuprolide versus continuous oral contraceptives in the treatment of endometriosis-associated pelvic pain. Fertil Steril. 2011;95:1568-1573.

57. Chapron C, Souza C, Borghese B, et al. Oral contraceptives and endometriosis: the past use of oral contraceptives for treating severe primary dysmenorrhea is associated with endometriosis, especially deep infiltrating endometriosis. Hum Reprod. 2011;26:2028-2035.

58. Vercellini P, Somigliana E, Viganò P, De Matteis S, Barbara G, Fedele L. Post-operative endometriosis recurrence: a plea for prevention based on pathogenetic, epidemiological and clinical evidence. Reprod Biomed Online. 2010;21:259-265.

59. Vlahos N, Vlachos A, Triantafyllidou O, Vitoratos N, Creatsas G. Continuous versus cyclic use of oral contraceptives after surgery for symptomatic endometriosis: a prospective cohort study. Fertil Steril. 2013;100:1337-1342.

60. Seracchioli R, Mabrouk M, Frascà C, et al. Long-term cyclic and continuous oral contraceptive therapy and endometrioma recurrence: a randomized controlled trial. Fertil Steril. 2010;93:52-56.
61. Vercellini P, Somigliana E, Daguati R, Vigano P, Meroni F, Crosignani PG. Postoperative oral contraceptive exposure and risk of endometrioma recurrence. Am J Obstet Gynecol. 2008;198:504. e1-e5.

62. Vercellini P, De Matteis S, Somigliana E, Buggio L, Frattaruolo MP, Fedele L. Long-term adjuvant therapy for the prevention of postoperative endometrioma recurrence: a systematic review and meta-analysis. Acta Obstet Gynecol Scand. 2013;92:8-16.

63. Tanmahasamut P, Rattanachaiyanont M, Angsuwathana S, Techatraisak K, Indhavivadhana S, Leerasiri P. Postoperative levonorgestrel-releasing intrauterine system for pelvic endometriosis-related pain: a randomized controlled trial. Obstet Gynecol. 2012;119: 519-526.

64. Abou-Setta AM, Houston B, Al-Inany HG, Farquhar C. Levonorgestrelreleasing intrauterine device (LNG-IUD) for symptomatic endometriosis following surgery. Cochrane Database Syst Rev. 2013;1: CD005072.

65. Zhou J, Lei ZW, Lü JQ, et al. [Conservative surgery combined with depot medroxyprogesterone acetate in treatment of moderate or severe endometriosis]. Zhonghua Fu Chan Ke Za Zhi. 2005;40:5-8. Chinese.

66. Goldstein DP, deCholnoky C, Leventhal JM, Emans SJ. New insights into the old problem of chronic pelvic pain. J Pediatr Surg. 1979; $14: 675-680$

67. American College of Obstetricians and Gynecologists Adolescent Health Care Committee Opinion. Adolescents and long-acting reversible contraception: implants and intrauterine devices. October 16, 2012. Available from: http://www.acog.org/About-ACOG/ACOGDepartments/Adolescent-Health-Care/Adolescents-and-Long-ActingReversible-Contraception/Accessed April 12, 2015.

68. Risser WL, Geftera LR, Barratt MS, Risser JMH. Weight change in adolescents who used hormonal contraception. J Adolesc Health. 1999;24:433-436.

69. Mangan SA, Larsen PG, Hudson S. Overweight teens at increased risk for weight gain while using depot medroxyprogesterone acetate. $J$ Pediatr Adolesc Gynecol. 2002;15:79-82.

70. Williams RL, Hensel DJ, Fortenberry JD. Self-administration of subcutaneous depot medroxyprogesterone acetate by adolescent women. Contraception. 2013;88:401-407.

71. Bahamondes MV, Hidalgo MM, Bahamondes L, Monteiro I. Ease of insertion and clinical performance of the levonorgestrel-releasing intrauterine system in nulligravidas. Contraception. 2011;84: e11-e16.

72. Pillai M, O’Brien K, Hill E. The levonorgestrel intrauterine system (Mirena) for the treatment of menstrual problems in adolescents with medical disorders, or physical or learning disabilities. BJOG. 2010;117:216-221.

73. Suhonena S, Haukkamaa M, Jakobsson T, Rauramo I. Clinical performance of a levonorgestrel-releasing intrauterine system and oral contraceptives in young nulliparous women: a comparative study. Contraception. 2004;69:407-412.

74. Yoost J, LaJoie AS, Hertweck P, Loveless M. Use of the levonorgestrel intrauterine system in adolescents with endometriosis. J Pediatr Adolesc Gynecol. 2013;26:120-124.

75. Al-Jefout M, Palmer J, Fraser IS. Simultaneous use of a levonorgestrel intrauterine system and an etonogestrel subdermal implant for debilitating adolescent endometriosis. Aust $N$ Z J Obstet Gynaecol. 2007;47:247-249.

76. Dinerman LM, Wilson MD, Duggan AK, Joffe A. Outcomes of adolescents using levonorgestrel implants vs oral contraceptives or other contraceptive methods. JAMA Pediatrics. 1995;149:967-972.

77. Lewisa LN, Doherty DA, Hickey M, Skinner SR. Implanon as a contraceptive choice for teenage mothers: a comparison of contraceptive choices, acceptability and repeat pregnancy. Contraception. 2010;81: 421-426. 
Open Access Journal of Contraception

Dovepress

\section{Publish your work in this journal}

Open Access Journal of Contraception is an international, peerreviewed, open access, online journal, publishing original research, reports, reviews and commentaries on all areas of contraception. In addition to clinical research, demographics and health-related aspects, the journal welcomes new findings in animal and preclinical studies

relating to understanding the biological mechanisms and practical development of new contraceptive agents. The manuscript management system is completely online and includes a very quick and fair peer-review system. Visit http://www.dovepress.com/testimonials.php to read real quotes from published authors.

Submit your manuscript here: http://www.dovepress.com/open-access-journal-of-contraception-journal 